\title{
A POLÍTICA FISCAL E TRIBUTÁRIA A PARTIR DO GOVERNO LULA: MUDANÇAS COGNITIVAS E INSTITUCIONAIS POR INSTRUMENTOS
}

\section{Fiscal policy and taxation from government lula: cognitive and institutional change by instruments}

\author{
Melina de Souza Rocha Lukic \\ Fundação Getúlio Vargas - Escola de Direito - FGV - Rio de Janeiro - Brasil
}

Resumo: A partir do segundo mandato de Lula (2007-2010), após o país ter conquistado a estabilidade fiscal e devido à crise de 2008, a orientação da política fiscal e tributária se volta para a competitividade internacional e 0 desenvolvimento do país. Lula passa a adotar políticas monetárias e fiscais "'anticíclicas"', a fim de recuperar o nível de atividade econômica o mais rápido possível. Esta virada foi feita por alterações e introdução de novos instrumentos da tributação, principalmente através de isenções fiscais e redução de tributos sem, contudo, romper com os princípios do paradigma anterior, centrado na estabilização econômica e fiscal. Assim, tais mudanças foram feitas por meio de modificações nos instrumentos da matriz cognitiva e normativa do paradigma e seguindo um processo de sedimentação institucional.

Palavras-Chave: Tributação, Política Fiscal, Análise Cognitiva, Neoinstitucionalismo

Abstract: From the second term of Lula (2007-2010), after the country won fiscal stability and due to the 2008 crisis, the stance of fiscal and tax policy turns to international competitiveness and development. Lula adopts "'countercyclical'" fiscal and monetary policies in order to recover the level of economic activity as quickly as possible. This change was made by modifications and introduction of new instruments of taxation, mainly through tax exemptions and tax reductions without, however, breaking with the principles of the previous paradigm, centered on economic and fiscal stabilization. Thus, such changes were made by modifications in the instruments of the cognitive and normative paradigm matrix and following a process of institutional sedimentation.

keywords: Taxation, Fiscal Policy, Cognitive Analysis, Neoinstitutionalism

Revista do Direito da UNISC, Santa Cruz do Sul, v.2, n. 46, p. 135-158, maio - ago. 2015. 


\section{INTRODUÇÃO}

O presente artigo tem por objetivo uma análise da mudança da política tributária praticada desde 2007 a partir de duas das variáveis levadas em conta pelas correntes neoinstitucionalistas que explicam processos de mudanças em políticas públicas (Hall, Taylor, 1997): as ideias e as instituições. Através desta perspectiva, evidenciaremos que o segundo mandato de Lula (2007-2010) é caracterizado por uma mudança tanto em termos cognitivos como institucionais, feita através de alterações nos instrumentos da política fiscal e tributária do Brasil. Após um período no qual a necessidade de estabilização econômica e de ajuste fiscal determinaram os caminhos da política tributária; a partir deste momento, anuncia-se um novo rumo nos objetivos do paradigma da tributação, agora voltado ao desenvolvimento e à competitividade internacional. Essa alteração foi feita em parte como uma resposta à crise de 2008, quando o governo teve que fazer ajustes adicionais na sua política econômica e fiscal. O governo brasileiro respondeu à crise com medidas inovadoras em comparação com a história recente do Brasil. Ao contrário das crises anteriores e do que ocorreu na maioria dos países, Lula adotou medidas monetárias e orçamentárias anticíclicas com a finalidade de recuperar o nível de atividade econômica o mais rápido possível.

Esta mudança de orientação do paradigma teve por consequencia a implementação ou alterações institucionais como o Programa de Aceleração do Crescimento e a redução de impostos e desonerações em várias áreas (setor elétrico, automóveis, produtos da linha branca, folha de salários). Tais medidas representam uma tentativa de estímulo à economia e à produção nacional e tem por fim adaptar o sistema aos novos princípios.

Em termos institucionais, a implementação de medidas de política tributária passou a uma etapa de mudança incrementalista (Thelen e Mahoney, 2010) na qual mudanças pontuais foram realizadas com o principal objetivo de se estabelecer um sistema eficaz e desenvolver o país. Ou seja, a palavra de ordem passou a ser a eficácia do sistema, crescimento e desenvolvimento do país e a competitividade internacional. Entretanto, as mudanças cognitivas e institucionais realizadas para atingir tais objetivos não romperam com a

Revista do Direito da UNISC, Santa Cruz do Sul, v.2, n. 46, p. 135-158, maio - ago. 2015. 
estabilidade econômica e fiscal, princípios que representavam o eixo central do paradigma neoliberal.

Assim, o objetivo do presente artigo é verificar que, mesmo se reformas substanciais do sistema tributário não tenham ocorrido desde 1988 em virtude do conflito de interesses (Lukic, 2012a, 2012b), mudanças tanto cognitivas como institucionais na orientação da política fiscal e tributária foram feitas através da implementação ou modificação de certos instrumentos, principalmente após 2008. À luz de teorias neoinstitucionalistas e da abordagem cognitiva de políticas públicas, analisaremos quais foram as razões para estas mudanças e como elas têm sido implementadas.

\section{ANALISAR A MUDANÇA DA POLÍTICA PÚBLICA ATRAVÉS DAS IDEIAS E INSTITUIÇÕES}

No que se refere às ideias, a análise será baseada em autores da abordagem cognitiva de políticas públicas ${ }^{1}$, dando atenção principalmente aos processos de mudança dos paradigmas de política pública tal como identificado por Hall $(1993,1997)$ e Surel $(1997,1995)$. Em seu estudo sobre a política macroeconômica na Grã-Bretanha, Hall define um paradigma da política como um "quadro de idéias e normas que indica não só os objetivos da política pública e o tipo de instrumentos que podem ser usados para alcançá-los, mas também a natureza dos problemas a que vão supostamente lidar" (Hall, 1993, p. 297). No caso da tributação brasileira, a Constituição de 1988 trouxe a previsão de um paradigma mais descentralista de sistema tributário, enquanto o contexto econômico dos anos 1990 fez com que a política fiscal e tributária atendesse a princípios orientados por um paradigma neoliberal. Entretanto, veremos no presente artigo que a partir do segundo mandato do governo Lula, o paradigma da tributação tem seguido uma orientação mais voltada ao desenvolvimento e ao crescimento econômico.

Por sua vez, sobre o conteúdo dos paradigmas, Müller e Surel (1998) indicam quatro elementos que, juntos, formam a sua "matriz cognitiva e

\footnotetext{
${ }^{1}$ Esta abordagem analisa "a política pública como matrizes cognitivas e normativas, como sistemas de interpretação da realidade, dentro das quais diferentes atores públicos e privados podem inscrever sua ação" (Müller, Surel, 1998, p. 47), portanto, o foco será sobre o estudo das representações, idéias e imagens vinculadas à política tributária.
}

Revista do Direito da UNISC, Santa Cruz do Sul, v.2, n. 46, p. 135-158, maio - ago. 2015. 
normativa" ${ }^{2}$, responsável pela estruturação e a definição do comportamento dos atores e, portanto, do conteúdo da ação pública. A matriz cognitiva e normativa consiste em primeiro lugar em princípios gerais e abstratos e valores compartilhados que são então derivados em princípios mais específicos, que permitem "operacionalizar os valores gerais em um campo ou uma política específica" (Müller, Surel, 1998, p. 49). No final, estes elementos cognitivos e normativos definem os métodos - formas práticas de se chegar aos objetivos bem como os instrumentos ${ }^{3}$ para a realização dos valores e objetivos (Müller, Surel, 1998, p. 50).

Veremos no presente artigo como as mudanças nos princípios mais gerais do paradigma da política tributária durante o segundo mandato de Lula resultaram em alterações pontuais ou introdução de novos instrumentos, através de medidas como desonerações a certos setores, por exemplo.

A abordagem baseada em paradigmas, em contraste com a noção de referencial proposta por Jobert e Muller (1987), fornece uma análise mais dinâmica em termos de evolução dos componentes da matriz cognitiva e normativa, crise e transformação do paradigma e, portanto, da política pública em si. Assim, os componentes do paradigma sofreriam mudanças em duas ou três fases: um período de prepolitica seguido de um período de política pública normal e um período de crise. Esta crise do paradigma pode ocorrer por vários motivos e pode ser caracterizada como um "problema em políticas públicas" (Surel, 1995, p. 142). A este respeito, Hall afirma que diferentemente de processos de ajuste de políticas públicas que não causam limites globais a um determinado paradigma, uma mudança de paradigma é marcada "por mudanças radicais nos termos recorrentes do discurso da política pública" (Hall, 1993, p. 279). Müller e Surel definem a "crise da política pública" como a "fase de ação pública, durante a qual as representações dominantes não conseguem interpretar a evolução de um campo social de forma satisfatória

2 A matriz cognitiva e normativa foi utilizada por Muller e Surel (1998) como um termo genérico para integrar os conceitos semelhantes das três correntes teóricas da análise cognitiva de políticas públicas: os referenciais (Jobert e Müller, 1987), os sistemas de crenças (Sabatier, Jenkins-Smith, 1993) e os paradigmas (Hall, 1993)

3 Os instrumentos específicos são as ferramentas que permitem a realização prática e concreta do paradigma como um todo. No caso de políticas públicas, Surel cita como exemplos a votação de uma lei e/ou a criação de uma instituição específica (Surel, 1995, p. 135).

Revista do Direito da UNISC, Santa Cruz do Sul, v.2, n. 46, p. 135-158, maio - ago. 2015. 
para as partes interessadas e, desse modo, não pode mais estruturar e legitimar com êxito a ação do estado" (Müller, Surel, 1998).

Uma das consequências desta crise de paradigma é a busca de novas definições e soluções para os problemas. É, portanto, um retorno às mesmas características da primeira fase - de emergência - com uma disputa dos atores em torno do novo paradigma que legitimará a estruturação de um determinado setor. Esta fase dá origem a uma mudança de políticas públicas, a partir do momento em que a perda dos referenciais legítimos leva à formulação de paradigmas concorrentes trazidos pelos atores em conflito. Esta situação tem por consequência a formação de um acordo em torno do paradigma que eventualmente passará a organizar a política pública. Inicia-se, finalmente, um novo período de estabilização do campo cognitivo e do sistema de atores (Surel, 1995, p. 143).

Hassenteufel (2008) observa um segundo elemento no processo de mudança de paradigmas de políticas públicas, não levado em consideração nas análises de Hall. Trata-se do elemento representado pelas regras institucionais que regem as interações entre os atores e trazem efeitos sobre os instrumentos e os objetivos da política pública (Hassenteufel, 2008, p. 228). Dessa forma, o objeto de análise será também considerado a partir da dinâmica institucional. A partir desta variável, será possível analisar como as instituições e regras enraizadas podem ter consequências sobre 0 comportamento e os interesses das partes interessadas, influenciando o equilíbrio de forças e a dinâmica do processo de mudança. Por esta dimensão também se pode analisar os mecanismos de aprendizagem, margem de manobra e restrições dos atores interessados na tomada de decisão.

Nesta linha, Pierson (2000) desenvolveu o conceito de dependência de trajetória (path dependence) a partir da análise de "processo de retorno crescentes" (increasing returns process) (Pierson, 2000, p. 252). Em outras palavras, este conceito corresponde a um "processo de autorreforço de uma seleção inicial cuja irreversibilidade cresce ao longo do tempo" (Pierson, 2000, p. 252) e permite, portanto, "explicar a natureza constrita das escolhas presentes" tendo em vista que as opções do possível são determinadas pelo existente (Hassenteufel, 2008, p. 242). A análise de dependência de trajetória parte de dois elementos-chave: o aumento dos custos da mudança de um v.2, n. 46, p. 135-158, maio - ago. 2015. 
paradigma para outro ao longo do tempo, a atenção para as questões de tempo e sequência, distinguindo os momentos de formação ou de conjuntura dos períodos que reforçam os caminhos divergentes (Pierson, 2000, p. 251). Assim, as questões da temporalidade e o processo histórico estão no centro da análise do processo de dependência de trajetória (Pierson, 2000).

Diante das críticas endereçadas à corrente teórica da dependência de trajetória ${ }^{4}$, propõe-se também um estudo das dinâmicas e condicionantes das mudanças institucionais, tal como sugerido pelos estudos de Thelen e Mahoney (2010). Thelen (2003) sugeriu uma análise da persistência institucional para além dos efeitos de retorno crescentes, levando em conta a lógica da evolução e da mudança institucional, ou seja: um estudo mais profundo do "efeito cumulativo de mudanças contínuas, mas sutis, dos arranjos institucionais que persistem por longos períodos de tempo" (Thelen, 2003). De acordo com Thelen "na verdade, muitas instituições políticas são interessantes de estudar, precisamente porque, através da observação, o impressionante é ver como, pouco e ao mesmo tempo muito, elas mudaram com o tempo" (Thelen, 2003). É esta continuação misturada com elementos de transformação institucional que mantém a instituição compatível com as mudanças econômicas, políticas e sociais. Assim, Thelen completa as análises de dependência de trajetória e os modelos de equilíbrio pontuado com outras ferramentas conceituais, tendo em conta a lógica de evolução e mudança institucional, representada por fenômenos de sedimentação (layering) e de conversão. Estas ferramentas incorporam elementos da dependência de trajetória e permite entender "os processos através dos quais os arranjos institucionais são renegociados periodicamente de forma a alterar a sua forma e suas funções" (Thelen, 2003).

4 No entanto, apesar das teorias centradas no conceito de dependência de trajetória terem trazido maior precisão para as formulações em termos de "ponto de bifurcação" (critical junctures) e "'percursos históricos e efeitos de retroação", elas tendem a produzir uma separação bastante estrita de questões relacionadas à inovação e à reprodução institucional. Isso é, quando essas teorias concentram sua análise no modelo do equilíbrio pontuado e na abertura de janelas de oportunidades, nas quais as inovações dão origem a períodos de estagnação institucional ou bloqueio, o resultado é uma crença de que, "uma vez criadas, as instituições ou persistem ou entram em colapso quando ocorrem alguns choques exógenos" (Thelen, 2003). Em outras palavras, diante de choques exógenos, a idéia da literatura sobre a dependência de trajetória parece ser que "instituições persistirem e tornam-se cada vez mais enraizadas ou então elas são abandonados" (Thelen, 2003).

Revista do Direito da UNISC, Santa Cruz do Sul, v.2, n. 46, p. 135-158, maio - ago. 2015. 
O ponto focal de Thelen é assim o fato de que a continuidade institucional não depende somente de um efeito de retroação (feedback) positiva, mas também de um processo de transformação institucional com a integração de novos atores e adaptação às mudanças do contexto econômico e político. Estes dois critérios desempenham um papel central na análise da evolução do sistema fiscal do Brasil. O argumento desenvolvido nas partes seguintes é que pequenas alterações no sistema tributário ocorreram por causa das mudanças no ambiente econômico e político do país.

Em um livro mais recente, Thelen e Mahonay (2010), com mais profundidade, desenvolvem a ideia de que "as instituições mudam muitas vezes de forma sutil e gradual ao longo do tempo". Estas mudanças trazem, como em casos de súbitas e profundas transformações, consequências para a determinação do comportamento humano e para os resultados políticos importantes. De acordo com os autores, enquanto a maioria da literatura sobre alterações institucionais enfoca nos choques externos, que geram reconfigurações institucionais radicais, é muito importante se analisar as mudanças ocorridas em razão de desenvolvimentos endógenos que muitas vezes acontecem de maneira incremental (Thelen, Mahonay, 2010). Os autores propõem, assim, uma análise dinâmica para explicar este tipo de alterações, com base não só em abordagens baseadas na distribuição de poder ${ }^{5}$, mas também atentos às questões de conformidade (compliance $)^{6}$.

\footnotetext{
${ }^{5}$ No que se refere à distribuição de poder, "instituições estão cheias de tensão porque inevitavelmente levantam considerações relativas aos recursos, o que invariavelmente traz consequências distributivas" (Thelen, Mahonay, 2010). Ou seja, todas as regras ou expectativas que moldam a ação pública terão implicações desiguais no que diz respeito à alocação de recursos. Esta distribuição desigual de poder tem um impacto sobre os interesses e as motivações dos atores na continuidade ou na mudança de uma determinada instituição. "Aqueles que se beneficiam do regime existente podem ter uma preferência objetiva para a continuidade, mas esta continuidade exige mobilização de apoio político, bem como, muitas vezes, de esforços ativos para resolver ambiguidades institucionais em seu favor" (Thelen, Mahonay, 2010). Portanto, se a instituição representa compromissos duráveis ou igualmente disputados de algumas coalizões, elas sempre são vulneráveis às flutuações e propícias para mudar. Uma das fontes de mudança será, assim, vinculada ao equilíbrio de poder, que se pode alterar através de modificações no ambiente e reconfiguração das forças.

6 Com relação à conformidade, Thelen e Mahonay (2010) afirmam que "a necessidade de respeitar as instituições carrega sua própria dinâmica de mudança potencial, não só pela natureza politicamente contestada das regras institucionais, mas, também, o que é importante, por uma certa abertura na interpretação e na aplicação destas regras" (Thelen, Mahonay, 2010). Dado que a ambiguidade é uma característica das regras, atores com interesses conflitantes disputam as aberturas oferecidas por esta ambiguidade, porque "a interpretação e a implementação podem ter consequências profundas para a alocação de recursos e para os resultados concretos" (Thelen, Mahonay, 2010). Assim, a variável conformidade permite
}

Revista do Direito da UNISC, Santa Cruz do Sul, v.2, n. 46, p. 135-158, maio - ago. 2015. 
Assim, os autores propõem um novo quadro para identificar e explicar os tipos de mudança institucional baseado nas características da instituição em questão e no contexto político. A partir do esquema desenvolvido pela Thelen (2003) e Streeck e Thelen (2005), quatro tipos de mudança podem ser identificadas: deslocamento (displacement), sedimentação (layering), deriva (drift) e conversão (conversion). Para fins do presente estudo, interessa-nos aprofundar o primeiro tipo - o "deslocamento" - que está presente quando as regras existentes são substituídas por novas. Este tipo de mudança é muitas vezes abrupta e radical, mas também pode ser um processo lento. "Isso pode acontecer quando novas instituições são introduzidas e competem diretamente (mais que completam) com o conjunto de antigas instituições. As novas instituições são muitas vezes introduzidas pelos atores que eram os "perdedores" sob o antigo regime" (Thelen, 2003). No que diz respeito ao sistema tributário, este tipo de mudança ocorreu no Brasil durante a Assembléia Constituinte de 1988, com a previsão de um novo paradigma de tributação, substituindo o sistema centralista anterior. No entanto, vemos que a mudança não foi completa, já que tivemos continuidades sobre alguns elementos do sistema, tais como a permanência do regime jurídico de arrecadação do ICMS.

O segundo tipo de mudança que nos importa é a «sedimentação institucional» (institutional layering). Trata-se de uma renegociação parcial de alguns dos elementos de uma determinada instituição, deixando todos os outras inalterados. Existe "sedimentação institucional" quando se conjugam elementos de bloqueio e inovação: as instituições são mantidas, mas passam por alterações em alguns de seus componentes, a fim de se adaptar ao novo contexto econômico ou político, ou devido a uma nova distribuição de poder entre os atores (Thelen, 2003). Em contraste com o "deslocamento", neste caso "não se introduz completamente novas instituições ou regras, mas consiste muito mais em modificações, revisões ou adições para as já existentes" (Thelen, Mahoney, 2010). Este processo geralmente ocorre quando os atores em jogo não têm a capacidade de modificar as regras de origem ou de criar um novo sistema para substituir o que está em vigor. Assim, em vez

analisar "como atores projetam novas aplicações e interpretações de regras para orientar os resultados na direção de sua preferência" (Thelen, Mahonay, 2010).

Revista do Direito da UNISC, Santa Cruz do Sul, v.2, n. 46, p. 135-158, maio - ago. 2015. 
disso, esses atores "'trabalham dentro do sistema existente, adicionando novas regras abaixo ou ao lado das antigas" (Thelen, Mahoney, 2010). Se os defensores do status quo conseguem preservar o sistema atual, eles não são capazes, no entanto, de evitar a introdução destas alterações que, apesar de menores, podem acumular-se e levar a uma grande mudança em longo prazo (Thelen, Mahoney, 2010). Este segundo tipo de mudança descreve o que aconteceu no caso brasileiro após 1988, onde certas regras - como, por exemplo, a Lei Kandir e a Lei de Responsabilidade Fiscal - foram incorporadas no sistema. Ambos os processos representam uma tentativa da União de restaurar o poder tributário perdido durante 1988 e uma forma de ajustar 0 sistema ao contexto econômico em que o país se encontrava.

No caso em análise, veremos a seguir que a mudança da política fiscal e tributária do país a partir do segundo mandato de Lula igualmente foi realizada, em termos cognitivos, por mudanças nos instrumentos da matriz cognitiva e normativa do paradigma e, em termos institucionais, por um processo de mudança do tipo "sedimentação", já que novas regras foram editadas em adição ao sistema anterior, sem modificar, portanto, abruptamente este.

\section{AS DISPUTAS EM TORNO DAS IDEIAS: AS MUDANÇAS DA POLÍTICA FISCAL}

Segundo uma corrente da abordagem cognitiva de políticas públicas, representada pelas análises de Hall (1993) e Surel (1995, 1997), após o processo de surgimento de uma determinada política pública, entramos no período da "política pública normal", caracterizado por uma estabilidade relativa durante o qual um paradigma se impõe e domina o campo da política pública. Em outras palavras, é um período relativamente calmo "no campo social, onde o equilíbrio de poder, representações e procedimentos são compartilhados e legitimados" (Surel, 1995, p. 142). No caso da política econômica e fiscal brasileira, pode-se questionar se o período normal corresponderia à implementação do paradigma neoliberal a partir da década de 1990, marcado por um movimento de liberalização da economia e no qual as determinações de organizações internacionais ocuparam um lugar central. Este paradigma surge após a "década perdida" de 1980, marcada por uma profunda crise

Revista do Direito da UNISC, Santa Cruz do Sul, v.2, n. 46, p. 135-158, maio - ago. 2015. 
económica, na qual pacotes de reformas foram recomendados pelas organizações internacionais (Fundo Monetário Internacional e Banco Mundial) para os Estados endividados da América Latina. Estas medidas compreendiam quase sempre uma disciplina orçamentária rigorosa para resolver a crise da dívida, acompanhada de recessão e hiperinflação. Assim, a intervenção fiscal, através da proposta de reformas fiscais, é um dos centros das medidas de estímulo.

No Brasil, a abertura da economia, as privatizações, a adoção de uma nova moeda e os acordos com o Fundo Monetário Internacional no contexto da crise global nos fins dos anos 90 influenciaram o paradigma, no sentido da necessidade de reduzir as despesas e aumentar as receitas fiscais para alcançar superávits primários. Se, em 1988, os objetivos do novo paradigma eram a descentralização de poderes e de receitas, agora, a tributação é inteiramente voltada para estabilização econômica e para o ajuste das contas públicas. A implementação do paradigma neoliberal teve como efeito, por um lado, a centralização do poder tributário nas mãos da União e, em segundo lugar, um aumento considerável da carga tributária a partir do início da década de 1990. Estas consequências foram realizadas através de alterações nos instrumentos do paradigma anterior, representadas pela criação de novos tributos (como a CPMF e a CSLL), pela introdução de limitações às competências tributárias e despesas de Estados e Municípios, tal como ocorreu com a Lei Kandir e a Lei de Responsabilidade Fiscal. Importante salientar que a imposição do paradigma neoliberal também impediu maiores mudanças no campo, como o que correu com a reforma tributária proposta sob o governo de Cardoso, que não foi aprovada por circunstâncias econômicas da época. Também neste período, podemos visualizar um processo de mudança institucional do tipo sedimentação, já que as novas regras não representaram uma modificação total do paradigma descentralista previsto na Constituição de 1988.

Com a chegada ao poder do Presidente Lula em 2003, o consenso nacional que o elegeu aliado à vontade de se fazer uma reforma tributária podem ser considerados como uma janela de oportunidade política (Kingdon, 2003; Favre, 1992) para o avanço da questão e para a aprovação das demandas das coalizões de causa interessadas na questão tributária. No v.2, n. 46, p. 135-158, maio - ago. 2015. 
entanto, apesar desta abertura, o processo de reforma tributária quase não avançou. Por outro lado, a política fiscal durante o primeiro mandato de Lula seguiu os mesmos princípios do paradigma do governo Cardoso: estabilização fiscal e ajuste das finanças públicas. Assim, a variável política, representada pela mudança presidencial, não influenciou as discussões sobre o assunto, pelo menos no início do governo. Tendo em conta o contexto econômico e compromissos assumidos com organismos internacionais, Lula continuou, portanto, o paradigma da política fiscal do seu antecessor, respeitando e garantido os acordos celebrados pelo Presidente Cardoso. Assim, o início de seu governo é fortemente marcado por um processo de path dependence, ou seja: continuação da política fiscal para manter e aprofundar o processo de estabilização e ajuste das finanças públicas. Para garantir essas conquistas, Lula tomou medidas para aumentar as receitas fiscais, através do aumento ou criação de algumas contribuições especiais, por exemplo. Estas pequenas mudanças podem ser vistas como mudanças incrementais e alterações dos instrumentos de acordo com a lógica de "sedimentação" (Thelen e Mahoney, 2010), a fim de preservar o grau de estabilização conquistada.

A primeira reforma proposta pelo governo Lula mostra bem esta situação: não representava uma mudança profunda das regras do sistema - em especial às relativas ao ICMS - mas medidas bastante específicas para atender às exigências de estabilidade fiscal, bem como algumas reivindicações dos grupos de interesses, seguindo assim uma lógica de "sedimentação" (Thelen e Mahoney, 2010). Apesar de propostas mais amplas terem sido apresentadas pelo relator da proposta na Câmara, uma reforma mais consistente não foi aprovada. Havia a presença de interesses muito divergentes, principalmente sobre a questão da distribuição das receitas tributárias entre os entes federativos. No entanto, a necessidade de aprovar rapidamente algumas mudanças para manter o nível de receitas do governo fez com que a discussão específica sobre o ICMS, objeto de disputas desde a Constituição de 1988, fosse adiada. Assim, devido à impossibilidade de se chegar a um consenso entre os atores, apenas as questões menos controversas e necessárias para a estabilização fiscal (tais como prorrogação da CPMF - Contribuição provisória sobre movimentações financeiras e a DRU - Desvinculação de Receitas da União) foram aprovadas, ao final, durante o primeiro mandato. Este processo

Revista do Direito da UNISC, Santa Cruz do Sul, v.2, n. 46, p. 135-158, maio - ago. 2015. 
nos mostra um contexto de poder de veto muito forte o que tornou, portanto, impossível, uma reforma mais profunda (do tipo «deslocamento» segundo a terminologia de Thelen e Mahoney (2010)). O primeiro mandato de Lula parece ter mostrado um processo de aprendizagem do governo em matéria de tomada de decisão. Os conflitos que a questão gerava sempre que era discutida, tiveram como consequencia limitar a amplitude da reforma tributária e a necessidade de que as mudanças fossem analisadas de forma repartida. Confrontado com a impossibilidade de reagrupar todos os interesses em um "consenso ambíguo" (Palier, 2003), a estratégia foi de remover os pontos mais polêmicos do projeto, para que as questões mais urgentes pudessem ser aprovadas. Esta estratégia, ao reduzir o poder de veto, permitiu a aprovação de certas alterações propostas, mesmo que pontuais.

No entanto, no início das eleições presidenciais de 2006, as dificuldades do modelo macroeconômico praticado desde 1999 para promover o crescimento emergiram. Dada a crise econômica e o aumento da taxa de juros no final do ano de 2005, a política econômica do país chegou numa encruzilhada: manter ou aprofundar as medidas recomendadas pela visão neoliberal ou seguir uma mudança de paradigma. $O$ esgotamento do modelo neoliberal tem contribuído para 0 surgimento de um paradigma "desenvolvimentista"7 (Barbosa e Souza, 2010). Neste contexto, o Presidente Lula pediu para a sua equipe a criação de um plano de medidas para "destravar" a economia e alcançar um crescimento anual do PIB de 5\% (Loureiro e Santos, 2011).

A mudança de paradigma da política econômica não ocorreu sem dificuldades. Oposições surgiram dentro do governo em torno da defesa neoliberal. Loureiro e Santos (2011) ressaltam a mudança de paradigma de política econômica que ocorreu no segundo mandato, tendo em vista que o governo já não precisava provar aos investidores que era capaz de cumprir as promessas da eleição de 2002. Somam-se a isso os anúncios de relatórios ao final de 2006 sobre a situação econômica do país, indicando os baixos níveis

\footnotetext{
7 Deve-se notar que o termo "desenvolvimentismo"' não é usado aqui de forma depreciativa, nem faz referência ao quadro teórico desenvolvido na década de 1970, pelo qual todas as sociedades convergem para um único modelo de modernidade. Trata-se de uma maneira de analisar e conceituar as ações relacionadas com a necessidade de implementar medidas para desenvolver o país.
}

Revista do Direito da UNISC, Santa Cruz do Sul, v.2, n. 46, p. 135-158, maio - ago. 2015. 
de crescimento econômico. Além disso, o contexto internacional da crise de 2008 influenciou fortemente o Brasil. Por fim, esta mudança na política macroeconômica do governo de Lula foi possível devido à saída de Palocci, Ministro da Fazenda, e de seus principais colaboradores, que vinham seguindo princípios orientados com o equilíbrio orçamentário e fiscal. Após a saída de Palocci, Lula indica uma equipe econômica que se identifica mais fortemente com o crescimento do mercado interno e que desejava estimular o consumo e aumentar o investimento. De acordo com Mattei e Magalhães (2011), esta medida representa uma "retomada da capacidade do estado de intervir na dinâmica econômica, principalmente em matéria de investimento". Em resumo, a mudança da equipe econômica foi um fator relevante na flexibilidade da política fiscal no início do segundo governo.

Se as políticas econômica e fiscal do governo de Cardoso, marcadas por superávits primários obtidos principalmente com o aumento de tributos foi seguida até 2006, um novo paradigma passa então a orientar tais políticas a partir deste ano. Os defensores deste novo paradigma "incrementalista" seguem três linhas de ação segundo Barbosa e Souza: a) a adoção de estímulos fiscais e monetários para acelerar o crescimento e aumentar o potencial de produção da economia, b) a aceleração do desenvolvimento social, através de transferências de renda e o aumento do salário mínimo e c) o aumento do investimento público e a retomada do papel do estado no planejamento a longo prazo (Barbosa e Souza, 2010). A ideia era que apenas um rápido crescimento da economia pudesse aumentar a demanda $\mathrm{e}$ produtividade e, portanto, os investimentos. De acordo com esta corrente, as transferências de renda poderiam ser implementadas sem causar um desequilíbrio das finanças públicas, desde que esta prática leve a um aumento das receitas fiscais para o governo. Neste sentido, a lógica de desenvolvimento foi projetada para direcionar este aumento da carga tributária para as transferências de renda para as famílias, a fim de manter uma pressão fiscal estável (Barbosa e Souza, 2010). Desta forma, as despesas sociais continuaram a subir durante o segundo mandato de Lula (de 11,9\% do PIB em 2002 para 13,45\% em 2008) (Mattei e Magalhães, 2011).

Revista do Direito da UNISC, Santa Cruz do Sul, v.2, n. 46, p. 135-158, maio - ago. 2015. 
Veremos a seguir, como este novo princípio do paradigma foi colocado em prática, através de mudanças por instrumentos e seguindo um processo de mudança institucional do tipo sedimentação.

\section{0 papel das instituições: o retorno do investimento público e as} desonerações tributárias do "Plano de Aceleração do Crescimento" (PAC)

Um dos objetivos principais do novo governo Lula foi fazer ressurgir o debate em torno da necessidade de investimento público, o qual tinha sido reduzido no período anterior devido à necessidade de se alcançar superávits primários. De acordo com um relatório do IPEA (2007), a redução do investimento público, particularmente no setor de infraestrutura e a ausência de um quadro jurídico para estimular o investimento privado neste setor, poderia trazer efeitos negativos sobre o crescimento econômico. Assim, o novo paradigma desenvolvimentista passa a defender um aumento do investimento público, especialmente em infraestrutura, para acelerar o crescimento e desenvolver a produção econômica. Para acompanhar este novo princípio, o governo propôs em 2007 o Plano de Aceleração do Crescimento (PAC) que continha um pacote de medidas para garantir um crescimento sustentável (IPEA 2007). Em suma, este plano proporcionou um aumento de gastos em investimentos públicos ${ }^{8}$. Para lidar com esses custos, o governo tem contado com o crescimento econômico e a manutenção (ou mesmo aumento) da carga tributária. Além disso, o investimento em infraestrutura não poderia interferir nas despesas sociais e na estabilidade do país. O PAC previa ações tanto para melhorar a gestão do estado quanto para estimular o investimento público e privado. As medidas previstas são ordenadas em cinco seções: 1) investimento em infraestrutura; (2) medidas orçamentárias de longo prazo; desonerações e melhorias para o sistema tributário; (4) a promoção de crédito e financiamento; (5) melhoraria nas condições de investimento.

\footnotetext{
${ }^{8}$ Em sua versão original, o PAC previa um investimento total de $\mathrm{R} \$ 504$ bilhões entre $2007 \mathrm{e}$ 2010 , dos quais $R \$ 58$ bilhões seriam investidos em transporte e logística, $R \$ 275$ bilhões para energia e $R \$ 171$ bilhões em infraestrutura social (Barbosa e Souza, 2010).

${ }^{9}$ Tais como controle dos salários dos funcionários públicos e o aumento do salário mínimo pela inflação.
}

Revista do Direito da UNISC, Santa Cruz do Sul, v.2, n. 46, p. 135-158, maio - ago. 2015. 
No que se refere especificamente às medidas tributárias, o PAC previu cortes de tributos para estimular o investimento privado e aumentar o consumo. Além disso, as desonerações incialmente previstas pelo PAC se aprofundaram em 2008, com o lançamento da política de desenvolvimento da produção. Os dois planos trouxeram previsão de redução de tributos, especialmente para 0 setor da construção, indústrias, infraestruturas pesadas e setor de alta tecnologia ${ }^{10}$ (computadores, produção de semicondutores, equipamentos para televisão digital). A tudo isto se soma uma mudança na tabela do imposto de renda, que beneficiou principalmente a classe média. Os planos também previam uma redução nas contribuições para a seguridade social, mas esta iniciativa fracassou: uma das razões foi a diminuição das receitas tributárias após a extinção da CPMF, fato que reduziu a margem de manobra do orçamento, conforme veremos a seguir. As medidas de desoneração fiscal contidas no PAC representaram um montante de $R \$ 1,41$ bilhão em 2007. Se incluirmos todas as medidas de desoneração no período, o total foi de $\mathrm{R} \$ 6,6$ bilhões em 2007 e $R \$ 11,5$ bilhões em 2008 (Ministério da Fazenda, 2008).

Em geral, o principal mérito da PAC foi o de aumentar o investimento público (0,4\% do PIB em 2003-2005; 0,7\% em 2006-2008) e estimular o investimento privado. No entanto, o plano não contribui com medidas destinadas a limitar o crescimento dos gastos, a fim de se encontrar um equilíbrio entre o seu financiamento e a manutenção da estabilidade fiscal. Assim, apesar das desonerações previstas em setores específicos, a implementação da PAC foi feita através de um aumento significativo das receitas tributárias. Este aumento ocorreu já no primeiro semestre do ano de 2007, devido às primeiras medidas de implementação do PAC (IPEA 2007). Este aumento das receitas tributárias foi realizado pela alteração da estrutura do PIB brasileiro que, até 2006, era baseado em exportações ${ }^{11}$ e, a partir de

\footnotetext{
${ }^{10}$ Para as empresas que fabricam televisores digitais e semicondutores, o PAC incluía a desoneraçaõ dos seguintes tributos: imposto de renda (16 anos), PIS, Cofins e IPI (15 anos), CIDE (12-16 anos). A aquisição de software usado por estas indústrias também seria beneficiada. Compras de determinados produtos siderúrgicos também se beneficiaram de uma redução de 5 a $0 \%$ da alíquota de IPI. Ganhos de fundos de investimento em infraestrutura estariam isentas do imposto recolhido sobre os ganhos. Computadores vendidos ao preço de até $\mathrm{R} \$ 4.000$ foram isentados da Cofins e do PIS. Estas medidas representaram uma renúncia fiscal de $R \$ 1,2$ bilhões em 2007 e $R \$ 2,3$ bilhões em 2008.

${ }^{11} \mathrm{O}$ saldo das exportações até 2008 aumentou as reservas internacionais e, portanto, permitiu o ajuste externo da economia brasileira, com uma dívida externa do setor público próxima de
}

Revista do Direito da UNISC, Santa Cruz do Sul, v.2, n. 46, p. 135-158, maio - ago. 2015. 
então, virou-se para o mercado interno. Desta forma, os impostos sobre consumo e os investimentos domésticos aumentaram fortemente as receitas fiscais, incluindo as relativas ao imposto de renda e imposto sobre as importações. Como resultado, o crescimento das receitas criou oportunidades tanto para financiar as ações previstas no PAC, como para a concessão de desonerações tributárias para setores específicos, sem comprometer a estabilidade fiscal já conquistada (IPEA 2007).

Outro fator teve efeitos sobre a tributação durante este período: a extinção da CPMF (contribuição provisória sobre operações financeiras) em 2007. No início de 2007, no lançamento do PAC, o governo federal decidiu não enviar imediatamente a proposta de prorrogação da CPMF ao Congresso, tendo em vista que o prazo de vigência seria até o final daquele ano. Ele preferiu, portanto, incluir esta questão numa proposta mais geral de reforma tributária, que foi apresentada ao congresso em meados de 2007 (Barbosa e Souza, 2010). No entanto, esta escolha era problemática para o governo federal, tendo em vista que, por um lado, a proposta de reforma tributária, devido à sua complexidade, não foi enviada ao Congresso em 2007 e que, por outro lado, a insatisfação da opinião pública sobre a CPMF foi se espalhando por causa desta indecisão (Barbosa e Souza, 2010). Assim, em termos de resultados, a proposta do governo federal para prorrogar mais uma vez a CPMF não foi aprovada pelo Parlamento.

Barbosa e Souza (2010) sublinham que o fim da CPMF causou, em paralelo com a diminuição das receitas fiscais da União de cerca de $1,4 \%$ do PIB, um aumento na demanda e, portanto, da inflação. Diante do fim da CPMF, o governo tem respondido à queda das receitas tributárias com um aumento do imposto sobre operações financeiras (IOF) e da contribuição Social sobre o lucro líquido (CSSL) para recuperar uma parte das receitas fiscais e evitar o aumento da demanda (Barbosa e Souza, 2010). Em seguida, o aumento dos preços internacionais das commodities resultou em efeitos inflacionários para 0 país. O governo, mais uma vez, lutou contra a aceleração da inflação através de medidas tributárias, como a redução dos impostos sobre o preço do trigo e seus derivados, a fim de reduzir o impacto do aumento dos preços saldo positivo e fez empréstimos ao FMI nos anos 2008 e 2009 (Mattei e Magalhães,) 2001.

Revista do Direito da UNISC, Santa Cruz do Sul, v.2, n. 46, p. 135- 158, maio - ago. 2015. 
internacionais e a inflação dos preços dos alimentos. No que diz respeito ao aumento dos preços internacionais do petróleo, o governo ainda respondeu com uma diminuição da contribuição de intervenção no domínio econômico (CIDE) sobre o combustível e o diesel.

A avaliação de todas as medidas de política econômica e fiscal desde que o governo Lula optou por um paradigma "desenvolvimentista" foi marcada por um crescimento médio anual do PIB: de 3,2\% em 2003-2005 para 5,1\% em 2006-2008 ${ }^{12}$. No entanto, iniciativas fiscais e tributárias durante o segundo mandato de Lula resultaram em uma redução do saldo primário do governo federal: de 2,5\% em 2003-2005 para 2,3\% do PIB em 2006-2008. Segundo Barbosa e Souza (2011), esta redução de apenas $0,2 \%$ do PIB, do saldo primário indica que o crescimento econômico induziu um aumento das receitas fiscais e financiou a expansão das despesas primárias. Além do PAC, 0 governo tomou medidas para aumentar o crédito para bens de consumo, os programas de transferência de renda e o salário mínimo. Estas alterações, de acordo com Loureiro e Santos (2011), indicam "que a política fiscal deixou de ser apenas um instrumento de garantia de solvência para os credores (credibilidade financeira) e adquiriu também o papel de instrumento de política de crescimento econômico e de melhoria da distribuição de renda".

Assim, a orientação da política fiscal e tributária no país mudou desde o segundo mandato de Lula: de um instrumento que visava atingir os excedentes primários previstos nos acordos internacionais passou a ser um meio para 0 crescimento e o desenvolvimento do país. Em outras palavras, a mudança na política fiscal e tributária consistia, basicamente, em uma inversão dos princípios gerais e abstratos do paradigma: se, até então, a idéia era considerar a austeridade fiscal como um pré-requisito para o crescimento e desenvolvimento; a partir deste momento o pensamento era que o crescimento econômico levaria a um equilíbrio fiscal (Loureiro e Santos, 2011). Portanto, a lógica era que o crescimento econômico poderia gerar mais receitas tributárias

\footnotetext{
${ }^{12}$ Este crescimento foi obtido, segundo Barbosa e Souza, graças ao controle da inflação e o declínio nas taxas de juros e, apesar de um aumento significativo em 2008, dos preços internacionais das matérias-primas agrícolas e minerais. Nota-se também dois outros fatores: 0 acúmulo de reservas internacionais, que reduziram a vulnerabilidade externa da economia e a valorização do real, que têm mitigado as pressões inflacionistas externas (Barbosa e Souza, 2011).
}

Revista do Direito da UNISC, Santa Cruz do Sul, v.2, n. 46, p. 135-158, maio - ago. 2015. 
que, por sua vez, permitiriam a continuação dos superávits necessários para equilibrar as finanças públicas. Além disso, o crescimento permitiria que se tivesse mais recursos para investimentos públicos e programas sociais. A política fiscal e tributária começou a adquirir então uma função adicional de instrumento para o crescimento econômico do país (Loureiro e Santos, 2011). No entanto, deve-se notar que a mudança do paradigma da política econômica e fiscal teve como limite o fato de não ameaçar os interesses da coalizão dos atores econômicos, cujas ideias foram expressas pelos dirigentes do Banco Central, de organizações internacionais e os atores do mercado financeiro (Loureiro e Santos, 2011). Em outras palavras, as políticas de desenvolvimento econômico e social têm avançado na medida em que elas não ameaçavam a credibilidade exigida pelo mercado financeiro. Neste sentido, Gobetti e Amado (2011) julgam que esta mudança de paradigma surgiu sem romper com as bases da política econômica ortodoxa, como a defesa da autonomia e a política restritiva do Banco Central e a definição das taxas de juro baseados em modelos que garantam a neutralidade da moeda.

Toda esta disputa de paradigma é representada, por exemplo, nas declarações da ministra Dilma Roussef, em 9 de novembro de 2005, ao criticar o ajuste orçamentário proposto pelo Ministro da Fazenda na época, Antonio Palocci. O ajuste previa um aumento do superávit primário e, de acordo com Dilma Rousseff: "Para a dívida pública não crescer, é preciso ter uma política de juros consistente, porque senão você enxuga gelo. Faço um superávit primário de um lado e aumento o fluxo e o estoque da dívida por outro" ( $O$ Estado de São Paulo, 9 de novembro de 2005, p. B01, in Gobetti, Amado, 2011).

Em seguida, com a crise internacional de 2008, o governo teve que fazer ajustes adicionais na política econômica e fiscal. Os principais efeitos da crise no país foram: uma diminuição forte e rápida da oferta de crédito interno, uma redução dos preços internacionais de matérias-primas e do comércio internacional que afetou, por consequencia, os exportadores brasileiros (Barbosa e Souza, 2010). O governo respondeu à crise por medidas inovadoras, em comparação com a história recente do Brasil, tendo em vista que o governo Lula adotou medidas monetária e fiscal "anticíclicas", ou seja, para recuperar o nível de atividade econômica tão rapidamente quanto possível

Revista do Direito da UNISC, Santa Cruz do Sul, v.2, n. 46, p. 135- 158, maio - ago. 2015. 
(Barbosa e Souza, 2011) ${ }^{13}$. Em matéria de tributação, as medidas de desoneração realizadas pelo governo desde 2007 foram mantidas, incluindo durante o período de crise.

Além disso, o governo tomou medidas tributárias de emergência, como isenções temporárias de impostos para aumentar o comércio e consumo. Por exemplo, no final de 2008, houve a redução do IPI dos automóveis para evitar um acúmulo de estoques na indústria e, ao longo de 2009, a mesma medida foi tomada para os setores de bens de consumo duráveis, materiais de construção, equipamentos, motocicletas, móveis e alimentos. O custo inicial das desonerações temporárias representou 0,3\% do PIB em 2009 (Barbosa e Souza, 2011). A inclusão das transferências extraordinárias para os governos dos Estados e Municípios em 2009 foi outra medida de emergência, a fim de manter os níveis de transferências de 2008, mesmo com a diminuição das receitas fiscais do governo federal em 2009. Além disso, o governo federal contribui com uma parte importante dos investimentos feitos em colaboração com os governos regionais, de forma a reduzir os gastos de Estados e Municípios. Finalmente, uma medida tributária estrutural tomada durante a crise foi a alteração das alíquotas do imposto de renda que passaram a ser de $7,5 \%, 15 \%, 22 \%$ e $27,5 \%{ }^{14}$.

Para concluir, podemos dizer que o paradigma da política fiscal e tributária sofreu modificações durante o segundo mandato do presidente Lula. Se durante o período 2003-2006, as políticas seguiram o modelo do governo Cardoso (marcado por uma agenda neoliberal e características conservadoras e ortodoxas), o segundo período (2007-2010) tem sido mais "incrementalista". Em outras palavras, este modelo é marcado por uma forte intervenção do estado na economia, uma recuperação da capacidade de investimento e um direcionamento do investimento privado para desenvolver a infraestrutura básica do país (Mattei e Magalhães, 2011). No entanto, deve ser dito que esta mudança não rompeu totalmente com a lógica do paradigma anterior. As

\footnotetext{
${ }^{13}$ Barbosa e Souza (2011) dividem as medidas tomadas pelo governo brasileiro à crise em três categorias: 1) as adotadas antes da crise, mas que ajudou o país neste período, 2) medidas de emergência, que foram implementadas após a crise e 3) medidas mais estruturais para combater os efeitos da crise. No que diz respeito à primeira categoria, observou-se o aumento do sistema de proteção da seguridade social, aumento do salário mínimo e do investimento público; as desonerações feitas pelo PAC e o PDP e a reestruturação de salários de funcionários públicos (Barbosa e Souza, 2011).

${ }^{14}$ Até 2008 , havia apenas três alíquotas: zero, $15 \%$ e $27,5 \%$.
}

Revista do Direito da UNISC, Santa Cruz do Sul, v.2, n. 46, p. 135-158, maio - ago. 2015. 
medidas do plano de aceleração do crescimento representam, portanto, alterações nos instrumentos do paradigma para que este se adapte à nova orientação e em um processo de sedimentação institucional.

No que diz respeito ao governo de Dilma Rousseff, esta já declarou durante as eleições sua discordância com a diminuição do superávit primário feito por Lula. Segundo a presidente, faz-se necessário manter as contas públicas em ordem (Valor Econômico, 31/10/2010). Dilma Roussef, durante sua campanha, salientou a necessidade de aumentar o investimento público e privado. Uma das maneiras de se alcançar esses objetivos seria através da redução de tributos sobre os investimentos (Valor Econômico, 31/10/2010). Dilma também destacou a necessidade de uma reforma tributária para unificar e reduzir o ICMS, bem como a contribuição para a seguridade social. Ela também declarou durante sua campanha que a reforma tributária seria uma prioridade para dar maior competitividade à economia brasileira, tendo em vista o caos tributário existente no Brasil (Valor Econômico, 31/10/2010). Com sua eleição, Dilma Rousseff tinha por missão ajustar as contas públicas, após a implementação de uma política mais expansionista de Lula. Assim, a Presidente realizou uma contingência do orçamento de $R \$ 50$ bilhões em 2011 e $R \$ 55$ bilhões em 2012 e um superávit primário de $R \$ 91$ bilhões em 2011. Estes números são, em parte, a consequência do aumento das receitas tributárias (de 11,69\% comparado a 2010) (Monteiro, 2011). No que se refere às medidas fiscais tomadas para incentivar setores económicos, Dilma Rousseff implementou o "Plano Brasil Maior" em abril de 2012. Trata-se de medidas para apoiar a indústria, tecnologia e comércio internacional. $O$ principal objetivo do plano é sustentar o crescimento econômico no contexto da crise internacional. A implementação do plano se deu através de medidas tributárias, entre outras, a desoneração de investimentos e exportações. Especificamente, o plano previa a redução do IPI sobre bens de capital, materiais de construção, caminhões e veículos, créditos tributários aos exportadores, mudança na imposição da contribuição para a seguridade social em vários outros setores, bem como a criação de um novo sistema de arrecadação para a indústria automobilística. Em abril de 2012, o governo aprofundou o plano e aumentou o número de setores que se beneficiam. Ainda não é possível analisar o impacto dessas medidas na economia, mas pode-se

Revista do Direito da UNISC, Santa Cruz do Sul, v.2, n. 46, p. 135-158, maio - ago. 2015. 
afirmar que Dilma tem seguido as mudanças nos princípios do paradigma fiscal iniciados por Lula.

\section{CONCLUSÃO}

Após o período no qual a estabilização econômica e o ajuste fiscal eram os princípios centrais que sustentavam o paradigma neoliberal da política fiscal e tributária, vimos no presente artigo que a partir do segundo mandato de Lula inicia-se um novo rumo nos objetivos da política pública em matéria de tributação. A preocupação de se estabelecer um sistema eficaz e desenvolver o país tornou-se o principal objetivo na execução da política fiscal. Passou-se, portanto, para um modelo voltado ao desenvolvimento, sem, no entanto, abandonar os postulados do paradigma anterior.

Vimos que, com o segundo mandato de Lula, houve uma mudança de ordem cognitiva e institucional na política fiscal e tributária que refletiram, por sua vez, mudanças de ordem macroeconômicas. O esgotamento do paradigma neoliberal, caracterizado pelos superávits primários sustentados principalmente pelo aumento de tributos, contribuiu para o surgimento de um novo paradigma com mudanças incrementais na política fiscal no final do ano de 2007. De acordo com este paradigma, seria necessário adotar medidas de estímulo fiscal e monetário para acelerar o crescimento e aumentar o potencial de produção da economia - garantindo uma redução das desigualdades sociais e um desenvolvimento do investimento público.

Em termos de tributação, este novo paradigma se concretizou através de mudanças instrumentais, como medidas de redução e isenção de tributos para estimular o consumo privado e impulsionar o investimento. Assim, este processo significa uma mudança nos princípios gerais e na orientação do paradigma da ação pública: se, desde a década de 1990, a austeridade fiscal estava no centro da política tributária; a partir do final de 2005 o governo brasileiro se volta para a busca do crescimento econômico. Tal mudança de orientação cognitiva foi acompanhada po rmudanças institucionais do tipo sedimentação, tendo em vista que não buscavam romper abruptamente com as

Revista do Direito da UNISC, Santa Cruz do Sul, v.2, n. 46, p. 135- 158, maio - ago. 2015. 
regras institucionais vigentes, mas somente ajustá-las ao novo contexto econômico do país.

Conclui-se, assim, que apesar de não ter havido a votação de uma reforma tributária ampla durante o período que mudasse significativamente 0 sistema tributário em vigor, em razão do conflito de interesses entre os atores, diversas mudanças sutis e pontuais foram realizadas e contribuiram para uma mudança cognitiva nos objetivos do paradigma da política fiscal e tributária brasileira.

\section{REFERÊNCIAS}

BARBOSA, N. e SOUZA, J. A. P. (2010) 'A Inflexão do Governo Lula: Política Econômica, Crescimento e Distribuição de Renda', in: E. Sader e M. A. Garcia (orgs.) Brasil: entre o Passado e o Futuro. São Paulo: Fundação Perseu Abramo e Editora Boitempo, 2010.

FAVRE Pierre, HAYWARD Jack, SCHEMEIL Yves (dir.), Etre gouverné, Paris : Presses de Sciences Po, 2003.

FOLHA DE SÃO PAULO, www.uol.com.br/fsp.

HALL, Peter A., "Policy Paradigms, Social Learning, and the State: The Case of Economic Policymaking in Britain" Comparative Politics, Vol. 25, No. 3 (Apr., 1993), pp. 275-296.

HALL, Peter A. TAYLOR, Rosemary, « La science politique et les trois néoinstitutionnalismes», Revue française de science politique, 47 (3-4), juin-août 1997, p. 469-496.

HASSENTEUFEL P., Sociologie politique : I'action publique, Paris, A. Colin, 2008.

IPEA, Boletim de conjuntura n 77, Brasilia: IPEA, jun 2007.

JOBERT, Bruno, MULLER, Pierre, L'état en action: politiques publiques et corporatismes, Paris, PUF, 1987.

KINGDON, John W., Agendas, alternatives, and public policies, New York: Longman, 2003.

LOUREIRO, Maria Rita, SANTOS, Fábio Pereira dos, GOMIDE, Alexandre de Ávila. Democracia, Arenas Decisórias e Política Econômica no Governo Lula. RBCS Vol. $26 n^{\circ} 76$ junho/2011.

Revista do Direito da UNISC, Santa Cruz do Sul, v.2, n. 46, p. 135-158, maio - ago. 2015. 
LUKIC, Melina Rocha. La fiscalité comme un problème public au Brésil: une analyse des coalitions de cause. Sarrebruck: Éditions Universitaires Européennes, 2012a, 143p.

LUKIC, Melina Rocha. A Tributação no Brasil analisada a partir da abordagem cognitiva de políticas públicas. Ética e Filosofia Política, v. I, p. 1, 2012b.

MATTEI, Lauro, MAGALHÃES, Luis Felipe, A Política Econômica Durante o Governo Lula (2003-2010): Cenários, Resultados e Perspectivas in PAULA, Marilene (org). "Nunca antes na história desse país"...? : um balanço das políticas do governo Lula. Rio de Janeiro, RJ: Fundação Heinrich Böll, 2011.

MULLER P., SUREL Y., L'analyse des politiques publiques, Paris, Montchrestien, 1998.

MINISTERIO DA FAZENDA, Reforma Tributaria, Brasilia, Ministério da Fazenda, 2008, retirado de http://www.fazenda.gov.br/portugues/documentos/2008/fevereiro/CartilhaReforma-Tributaria.pdf.

PALIER, Bruno, "Gouverner le changement des politiques de protection sociale » in FAVRE Pierre, HAYWARD Jack, SCHEMEIL Yves (dir.), Etre gouverné, Paris : Presses de Sciences Po, 2003.

PALIER, Bruno et SUREL, Yves. "Les 'trois is' et l'analyse de l'État en action" in Revue Française de Science Politique, vol. 55, no1, février 2005, p. 7-32.

PIERSON, Paul. "Increasing Returns, Path dependency, and Study of Politics". American Political Science Review, vol..94, n.2, june 2000, pp.251-267. SABATIER P., JENKINS-SMITH H. (dir.), Policy Change and Learning, Boulder, Westview Press, 1993.

SUREL, Yves, L'Etat et le livre : les politiques publiques du livre en France : 1957-1993, Paris: Harmattan, 1997.

SUREL, Yves, "Les politiques publiques comme paradigmes », in FAURE A., Pollet G., Warin P. (dir.), La construction du sens dans les politiques publiques, Paris, L'Harmattan, 1995.

THELEN Kathleen, How Institutions Evolve: Insights from ComparativeHistorical Analysis in James Mahoney and Dietrich Rueschemeyer, eds., Comparative Historical Analysis in the Social Sciences. New York: Cambridge University Press, 2003.

THELEN Kathleen e STREECK Wolfgang. Institutional Changes in Advanced Political Economies, In: Streeck W. e Thelen K. (ed.), Beyond Continuity: Institutional Change in Advanced Political Economies, Oxford: Oxford University Press, pp. 1-3, 2005.

Revista do Direito da UNISC, Santa Cruz do Sul, v.2, n. 46, p. 135-158, maio - ago. 2015. 
THELEN Kathleen MAHONEY, James, "A theory of gradual institutional change" in James Mahoney and Kathleen Thelen (eds.) Explaining Institutional Change: Ambiguity, Agency, and Power. Cambridge University Press, 2010, p.1-37.

TSEBELIS, George. Decision Making in Political Systems: Veto Players in Presidentialism, Parliamentarism, Multicameralism and Multipartyism. British Journal of Political Science, Vol. 25, No. 3 (Jul., 1995), 289-325.

VALOR ECONÔMICO. Dsiponível em: <www.valor.com.br>. Acesso: 18 ago. 2013

Revista do Direito da UNISC, Santa Cruz do Sul, v.2, n. 46, p. 135-158, maio - ago. 2015. 